\title{
The Information Content of Money in Forecasting Euro Area Inflation
}

Helge Berger and Emil Stavrev 



\title{
IMF Working Paper
}

\author{
European Department
}

The Information Content of Money in Forecasting Euro Area Inflation

Prepared by Helge Berger and Emil Stavrev*

Authorized for distribution by Jörg Decressin

July 2008

\begin{abstract}
This Working Paper should not be reported as representing the views of the IMF. The views expressed in this Working Paper are those of the author(s) and do not necessarily represent those of the IMF or IMF policy. Working Papers describe research in progress by the author(s) and are published to elicit comments and to further debate.

This paper contributes to the debate on the role of money in monetary policy by analyzing the information content of money in forecasting euro-area inflation. We compare the predictive performance within and among various classes of structural and empirical models in a consistent framework using Bayesian and other estimation techniques. We find that money contains relevant information for inflation in some model classes. Money-based New Keynesian DSGE models and VARs incorporating money perform better than their cashless counterparts. But there are also indications that the contribution of money has its limits. The marginal contribution of money to forecasting accuracy is often small, money adds little to dynamic factor models, and it worsens forecasting accuracy of partial equilibrium models. Finally, non-monetary models dominate monetary models in an all-out horserace.
\end{abstract}

JEL Classification Numbers:C11, C30, E31, E40

Keywords: Information content of money, inflation forecasting, New Keynesian model, DSGE model, P* model, Two-pillar Phillips curve, VAR model, general dynamic factor model, Bayesian estimation, euro area

Author’s E-Mail Address: helge.berger@fu-berlin.de; estavrev@imf.org.

* We would like to thank Henning Weber for helpful comments and suggestions. 


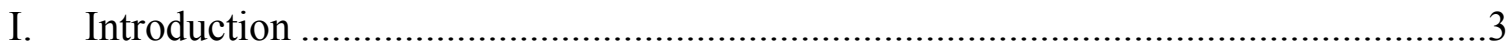

II. Related Literature ............................................................................................

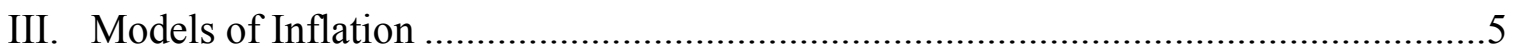

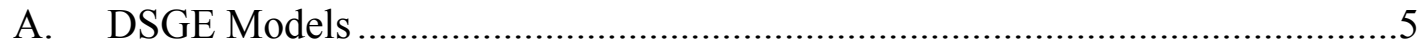

B. Partial Equilibrium Models ...................................................................

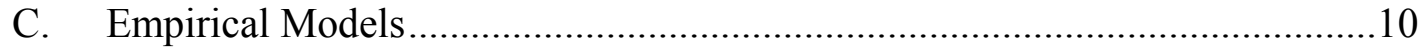

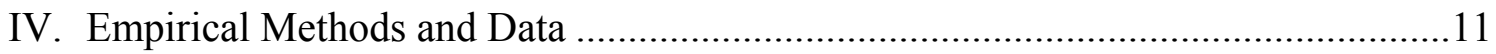

A. Estimation Techniques.............................................................................

B. Prior Distribution of Parameters for the Bayesian Estimates ...........................12

C. Forecasting and the Information Content of Money .........................................12

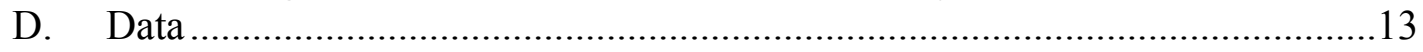

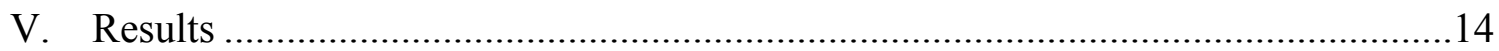

A. The Marginal Contribution of Money...............................................................14

B. Comparison of Money-Based Models ...........................................................17

C. Comparison Across All Models....................................................................

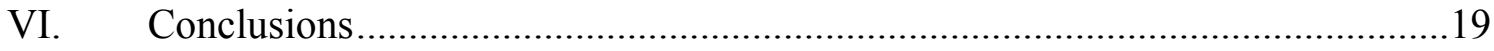

Figures

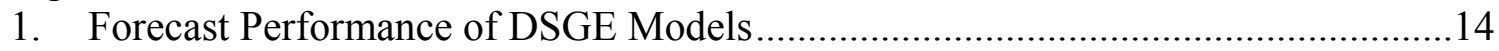

2. Forecast Performance of Empirical Models ...............................................................15

3. Forecast Performance of $\mathrm{P}^{*}$ and Phillips Curve Models ..........................................16

Tables

1. Out-of-Sample Forecasting Performance of Models ................................................18

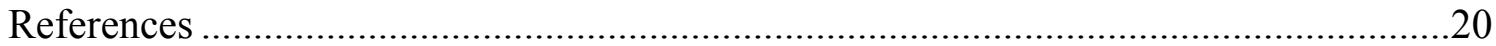

Appendices

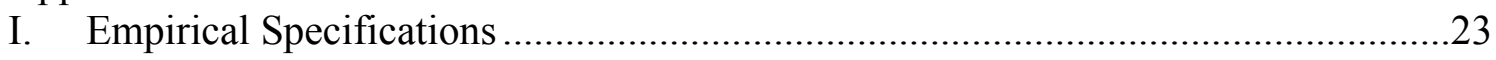

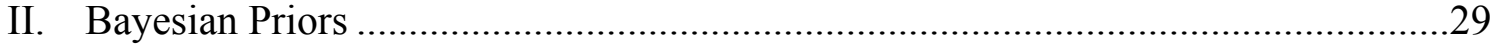




\section{INTRODUCTION}

Many Central Banks look at money as a source of information in their decision-making. For example, the European Central Bank (ECB) has assigned a special role for monetary aggregates as a cross-check of the economic analysis, supporting its inflation forecasts and risk assessment. A number of other central banks, in particular, the central banks of Japan and Switzerland, also follow monetary developments closely and incorporate monetary analysis in their core policy framework in a style reminiscent of the ECB's two pillar approach (Assenmacher-Wesche and others 2007). In addition, the Bank of England, as well as the central banks in New Zealand, Australia, and Sweden, regularly discuss monetary developments in one form or another (OECD 2007).

At the same time, there is an ongoing debate in the literature about the relevance of money for monetary policy making. At a theoretical level, the findings are not conclusive. For instance, standard models, such as the New Keynesian Model (NKM), attribute no role for money in the inflation dynamics and, hence, monetary policy (Woodford 2003). This outcome follows, in part, from the assumption of full (intra- and inter-temporal) separability between consumption and real money balances in the households' utility function. However, in models in which the separability assumption is lifted, money does play a structural or causal role by affecting both aggregate demand and supply and, ultimately, inflation (McCallum 2001, Nelson 2002). Another reason why monetary aggregates may matter could be informational frictions. For instance, a central bank that incompletely observes determinants of inflation, such as output, may gather relevant information from monetary aggregates, in particular if money demand is forward-looking (Nelson 2003).

With the theoretical discussion ongoing, the issue is ultimately an empirical question, but the empirical literature sends mixed signals, too. A number of studies concludes that money may provide relevant information for inflation in the euro area. Others reject this finding, and recent cross-country studies also cast doubt on a reliable link between money and inflation. One explanation for the heterogeneity in results is that the literature so far employs any number of inflation models, empirical approaches, and sample periods.

We contribute to the debate by documenting the information content of money for inflation in the euro area for a wide range of theoretical and empirical models, using a consistent framework and Bayesian and other estimation techniques. Our approach is to compare the out-of-sample forecasting accuracy of models with and without money within a given model class. The model classes include dynamic stochastic general equilibrium (DSGE) models along the lines of the NKM, partial equilibrium models ranging from the so-called two-pillar Phillips curve to the $\mathrm{P}^{*}$ model, and purely empirical model such as the general dynamic factor model (GDFM) approach. In addition, we also take a look at relative forecasting accuracy across these model classes. All models are initially estimated over the same training period, 1993 to 1999, and their inflation forecasting performance is assessed for the period 2000 to 2007.

There are several interesting results. First, we find that money contains relevant information for inflation in the sense that for a number of model classes the accuracy of out-of-sample inflation forecasts increases as monetary information is added. For instance, the generalized NKM approaches that, one way or the other, incorporate money balances, perform better than the cashless NKM baseline. Time-series models, too, seem to generally support the idea that money 
plays a role in forecasting inflation. However, within the class of GDFM and-somewhat surprisingly - partial equilibrium models including monetary information does little to improve inflation forecasting accuracy.

A second finding is that the relative performance of the money-based models suggests a "u-shaped" relationship between the degree of their theoretical underpinnings and their forecasting performance. The best empirical model and the best DSGE model are doing better than the best partial equilibrium model. As a corollary of this, it would seem that the information content of money may not be adequately captured by the change in monetary aggregates or other transformations of the money stock, as some of these partial models assume. Instead, a more explicit modeling of the dynamics and underlying theoretical structure of the money-inflation relationship may be called for.

Finally, there are indications that the contribution of money to the accuracy of inflation forecasting out-of-sample has its limits. The improvements in forecasting accuracy are often small, not all money-based approaches add to the precision of inflation predictions within their model class, and monetary models are dominated by non-monetary models overall.

The paper is organized as follows. Section II provides a brief summary of the related literature. Section III discusses theory. Section IV explains the empirical methods and discusses the data sources. Section V presents the estimation results, and Section VI concludes.

\section{RELATED LITERATURE}

A number of studies suggest that the indicator properties of money for inflation may be limited - either because money-based models do not perform well in a cross-country framework or because money is severely outperformed by other indicators. For example, Roffia and Zaghini (2007) and De Grauwe and Polan (2005) argue that the relationship between money and inflation across industrialized countries and time my be weaker than what is commonly thought. For the euro area, Gerlach and Svensson (2003) find that the growth rate of nominal M3 adds little to the forecasting accuracy of an output-gap based model of euro area inflation. Similarly, Stavrev (2006) finds that inflation forecasts for the euro area based on some quantity-theory inspired inflation models are outperformed by non-monetary approaches. And the OECD (2007) reports results from an euro area inflation forecasting horserace between alternative time-series models suggesting that money played a prominent role only up to 2000, but is out-performed by real time measures of the output gap as a predictor of inflation thereafter.

Others suggests that money-enhanced models can help forecasting euro area inflation. The Bundesbank (2005) and Fischer and others (2008) report that $\mathrm{P}^{*}$ models contain information on euro-area inflation. Gerlach (2004) and Assenmacher-Wesche and Gerlach (2006a, 2006b) show a significant contribution of longer-run movements in money growth (appropriately filtered) in two-pillar Phillips-curve type dynamic inflation. Gerlach and Svensson (2003) find that a real money gap representation of the $\mathrm{P}^{*}$ model adds to the predictive power of a conventional Phillips curve approach. Nicoletti-Altimari (2001), Hofmann (2008), and Scharnagl and Schumacher (2007) all find that M3 growth (or its trend) is useful for inflation forecasts at medium-term horizons. Finally, in a recent contribution, Berger and Österholm (2008a) confirm that M3 growth can help improve forecasting models of euro-area inflation in a 
mean-adjusted Bayesian VAR framework, but they also caution that the size of this improvement tends to be small. Interestingly, the result seems not to be an artifact of the particularities of the euro area: a related paper reports similar findings for M2 growth in the U.S. (Berger and Österholm 2008b).

A number of factors may explain these widely differing results. An important factor may be differences in the empirical approach. The literature has employed a wide variety of models, ranging from the purely empirical to more theory-guided. While these models incorporate money in different ways, and, in principle, allow a comparison with non-monetary approaches, these comparisons are rarely nested. This makes it difficult to identify the marginal contribution of money to inflation forecasting accuracy. In addition, the literature does not focus on a unified sample period. This could be relevant because, as D'Agostino and others (2006) stress, the predictability of macroeconomic variables has been lowered as macroeconomic volatility declined during the so-called great moderation. Finally, Woodford (2008) and Galí and others (2004) warn that establishing a structural or causal relationship between money and inflation requires use of structural dynamic equilibrium models, an approach not very common in the inflation forecasting literature so far.

In what follows, we will attempt to evaluate the information content of money in forecasting inflation in a systematic approach taking into account these considerations.

\section{MODELS OF INFLATION}

Our main approach is to evaluate the information content of money for inflation within three distinct classes of models: DSGE models, partial equilibrium models, and empirical models. In this section, we will describe, in turn, each model class and the potential role money plays within it. Appendix I lays out the full details of the specifications used in the empirical application.

\section{A. DSGE Models}

\section{The cashless New Keynesian Model}

The standard cashless NKM is based on an aggregate supply and an aggregate demand equation that, in combination with a monetary policy rule, determine the equilibrium path of inflation. The aggregate supply equation often combines Calvo-style price setting with price indexing (see, inter alia, Woodford 2003 and Christiano and others 2005). Profit maximizing firms setting prices take into account the current output gap and expected future price developments. In a log-linearized form around the steady state, the aggregate supply equation (or Philips curve) thus takes the form

$$
\hat{\pi}_{t}=\theta_{\pi} \hat{\pi}_{t-1}+\theta_{E \pi} E \hat{\pi}_{t+1}+\theta_{x} x_{t}+\varepsilon_{\pi, t}
$$

where $\hat{\pi}_{t}$ is the deviation of inflation from its (time-invariant) steady state, $x_{t}=y_{t}-y_{t}^{n}$ is the output gap, defined as the log deviation of output from its flexible-price potential, $\varepsilon_{\pi, t}$ is a cost-push shock, and the coefficients, fulfilling $\theta>0$, summarize the deep structural parameters 
of the underlying model. ${ }^{1}$ The expectations operator $E$ is based on the information set at period $t$.

Dynamic aggregate demand is derived from intertemporal household optimization based on a period utility function that may include real balances, but in the standard model is assumed to be fully separable in all its arguments. In this case, the Euler equation implies

$$
x_{t}=\phi_{E x} E x_{t+1}-\phi_{i}\left(\hat{i}_{t}-E \hat{\pi}_{t+1}\right)+\varepsilon_{x, t},
$$

where $\hat{i}_{t}$ is the deviation of the nominal interest rate controlled by the central bank from its steady state and $\varepsilon_{x, \mathrm{t}}$ is an aggregate demand shock. The coefficients $\phi>0$ summarize parameters in the households' utility function.

Finally, monetary policy determines inflation by setting the time path of nominal interest rates to anchor inflation expectations, which closes the model. For tractability, we opt for a Taylor-type rule

$$
\hat{i}_{t}=\kappa_{i} \hat{i}_{t-1}+\left(1-\kappa_{i}\right)\left(\kappa_{E \pi} E \hat{\pi}_{t+1}+\kappa_{x} x_{t}\right),
$$

where the coefficients $\kappa>0$ are defined such that that $\left(1_{\mathrm{NKM}}\right),\left(2_{\mathrm{NKM}}\right)$, and $\left(3_{\mathrm{NKM}}\right)$ describe a well-determined equilibrium. The rule states, quite plausibly, that monetary reacts with some inertia to deviations of expected inflation from its steady state (assumed to be identical with the central bank's inflation target) and the output gap.

The model determines inflation in equilibrium without any reference to money. Of course, if money is included in the utility function as another (and separable) argument, household optimization yields a standard money demand function. But in this case monetary developments merely mirror the behavior of the model's core variables without influencing equilibrium outcomes.

A variant of the above model introduces habit persistence in consumption. As, for instance, Fuhrer (2000) and Christiano and others (2005) show, habit persistence adds additional leads and lags of output to aggregate demand and supply and is thought to help the model capture important features of the data.

\section{Generalizations of the NKM Model Incorporating Money}

Money plays a more prominent role in generalized versions of the NKM model. For instance, taking into account financial frictions (Bernanke and others 1996, Diamond and Rajan 2006), informational frictions (Nelson 2002), or assuming non-separability of money and consumption in household utility (McCallum 2001) all introduce a structural or at least informative role for

\footnotetext{
${ }^{1}$ All variables of the NKM models discussed in Section III.A are expressed as deviations from their steady state levels, while Section III.B as well as Appendix I use levels.
} 
money with regard to inflation. In what follows, we will focus on the latter two arguments, which lend themselves readily to an empirical implementation.

As with the cashless baseline model, in addition, habit persistence in consumption can be added to the generalized NKM approaches.

\section{Adjustment costs and informational frictions}

One approach to give money a more important role in the NKM focuses on its potential informational function. For instance, Andrés and others (2007) argue that households have a (separable) preference for holding money, which adds money demand to the otherwise unchanged NKM framework. Assuming, in addition, that adjustment of the money stock is costly for households, real money demand is

$$
\hat{m}_{t}=\bar{\gamma}_{x} \hat{y}_{t}+\bar{\gamma} \hat{i}_{t}+\bar{\gamma}_{m} \hat{m}_{t-1}+\bar{\gamma}_{E m} E \hat{m}_{t+1}+\varepsilon_{m, t}
$$

where $\bar{\gamma}>0, \hat{y}_{t}$ is the deviation of the level of output from its steady state, and where $\hat{m}_{t}$ and $E \hat{m}_{t+1}$ are the current and the expected deviation of real balances from their steady state, respectively. Note that money demand is influenced by lagged as well as expected real balances, which implies that it will reflect the entire expected future time path of interest rates and output.

Nelson (2003) then argues that in the presence of informational frictions - for instance, if current private sector shocks are unknown to the central bank (see Aoki 2006) -incorporating money into the policy function will be optimal. ${ }^{2}$ While this will also hold in the absence of adjustment costs, the weight given to monetary aggregates in the policy rule is particularly large when money demand is forward-looking. Accordingly, we adjust the Taylor-type rule to

$$
\hat{i}_{t}=\widetilde{\kappa}_{i} \hat{i}_{t-1}+\left(1-\widetilde{\kappa}_{i}\right)\left(\widetilde{\kappa}_{E \pi} E \hat{\pi}_{t+1}+\widetilde{\kappa}_{x} x_{t}+\widetilde{\kappa}_{M} \hat{M}_{t}\right),
$$

with all $\widetilde{\kappa}>0$ and where $\hat{M}_{t}$ represents the deviation of nominal balances from their steady state value.

\section{Non-separability}

Another approach relaxes the within-period separability assumption of money and consumption. This causes both the present and the expected level of real balances, $\hat{m}_{t}$ and $E \hat{m}_{t+1}$, to enter as additional terms in the aggregate demand equation $\left(2_{\mathrm{NKM}}\right)$ (e.g., Andrés and others 2006). In addition to this indirect channel, non-separability will also introduce a direct effect of $m_{t}$ on

\footnotetext{
${ }^{2}$ An alternative argument for incorporating money in the interest rate equation could be that money, for reasons not captured in the structural model, helps to forecast inflation or the central bank shares the households' preference for a stable money stock. See Andrés and others (2007).
} 
inflation into price setting equation $\left(1_{\mathrm{NKM}}\right){ }^{3}$ Summarizing, aggregate inflation and aggregate demand become

$$
\begin{gathered}
\hat{\pi}_{t}=\widetilde{\theta}_{\pi} \hat{\pi}_{t-1}+\widetilde{\theta}_{E \pi} E \hat{\pi}_{t+1}+\widetilde{\theta}_{x} x_{t}-\widetilde{\theta}_{m} \hat{m}_{t}+\varepsilon_{\pi, t} \\
x_{t}=\widetilde{\phi}_{E x} E x_{t+1}-\widetilde{\phi}_{i}\left(i_{t}-E \hat{\pi}_{t+1}\right)+\widetilde{\phi}_{m} \hat{m}_{t}-\widetilde{\phi}_{E m} E \hat{m}_{t+1}+\varepsilon_{x, t},
\end{gathered}
$$

with $\widetilde{\theta}, \widetilde{\phi}>0 .{ }^{4}$ Household optimization will also yield a standard money demand function

$$
\hat{m}_{t}=\gamma_{x} \hat{y}_{t}-\gamma_{i} \hat{i}_{t}+\varepsilon_{m, t},
$$

with $\varepsilon_{m, \mathrm{t}}$ representing liquidity preference shocks and where the coefficients $\gamma>0$ are based on parameters in the households utility function. In addition, monetary policy is assumed to incorporate money balances along the lines of $\left(4_{\mathrm{NKMA}}\right)$.

\section{B. Partial Equilibrium Models}

A popular alternative to the general equilibrium approach are the reduced form or partial equilibrium models. While less complete in their description of the economic forces driving inflation, they are not completely without theoretical background and comparatively easy to implement.

\section{The Phillips curve with and without money}

A simple Phillips curve model of inflation may take the form

$$
\pi_{t}=\beta_{\pi} \pi_{t-1}+\beta_{x} x_{t}+\varepsilon_{\pi, t},
$$

where all $\beta>0$. The model assumes that the level of inflation, in addition to showing some inertia, is a positive function of the output gap. Its empirical relevance can be contrasted with generalized versions of the model taking into account monetary factors.

One recent extension is the so-called two-pillar Phillips curve, which adds long-run excess movements in money growth equation to $\left(1_{\mathrm{PC}}\right)$. The idea, broadly following the quantity theory of money, is that long-term movements of money unrelated to changes in output and interest rates help forecasting inflation (e.g., Gerlach 2004, Assenmacher-Wesche and Gerlach 2006a, 2006b). The long-term component of these variables is extracted using various filtering techniques and then added linearly to lagged inflation and the output gap,

\footnotetext{
${ }^{3}$ The reason is that forward-looking price setters apply the households' stochastic discount factor in their dynamic optimization problem, which, in turn, is influenced by money holdings.

${ }^{4}$ Note that the direct and indirect impact of contemporaneous money on inflation move into opposite directions, with the overall impact being a question of the underlying parameters and, thus, ultimately an empirical matter.
} 


$$
\pi_{t}=\beta_{\pi} \pi_{t-1}+\beta_{x} x_{t}+\alpha_{m} \Delta m_{t}^{L}+\alpha_{y} \Delta y_{t}^{L}+\alpha_{i} \Delta i_{t}^{L}+\varepsilon_{\pi, t},
$$

with $\beta_{x}>0$, and $\Delta m_{t}^{L}, \Delta y_{t}^{L}$, and $\Delta i_{t}^{L}$ representing the growth rate of the long-term component of real money balances, real GDP growth, and the nominal interest rate change, correspondingly. In addition, the assumptions hold that $\alpha_{r}>0$ and $\alpha_{m}=-\alpha_{y}=1$.

Another specification of the two-pillar Phillips curve uses the real money gap instead of long-run excess money growth. More formally, following Gerlach and Svensson (2003), the two-pillar Phillips curve takes the form:

$$
\pi_{t}=\beta_{\pi} \pi_{t-1}+\beta_{x} x_{t}+\alpha_{m}\left(m_{t}-m_{t}^{*}\right)+\alpha_{\Delta m}\left(\Delta m_{t}-\Delta m_{t}^{*}\right)+\varepsilon_{\pi, t},
$$

where, $m_{t}$ and $m_{t}^{*}$ are the real level of money balances and their equilibrium value, respectively, while $\Delta m_{t}$ and $\Delta m_{t}^{*}$ are the corresponding growth rates.

\section{The $\mathrm{P} *$ Model with and without money}

The $\mathrm{P}^{*}$ model, in its original representation, rests on the assumption that deviations of the log actual price level, $\mathrm{p}$, from the log equilibrium price level, $\mathrm{p}^{*}$, the so-called price gap, is a good predictor of future price adjustments and, thus, inflation. Broadly following Svensson (2000), the price gap can be related to inflation as follows:

$$
\pi_{t}=\alpha \pi_{t-1}+(1-\alpha) E \pi_{t}+\beta\left(p_{t-1}^{*}-p_{t-1}\right)+\varepsilon_{\pi, t},
$$

where $\alpha, \beta>0 .^{5}$

An expanded version of the $\mathrm{P}^{*}$ model includes money balances. As shown in Svensson (2000), the price gap can be related to the monetary gap or excess liquidity, $\widetilde{m}_{t}=m_{t}-m_{t}^{*}$, defined as the difference between the $(\log )$ real money stock and the $(\log )$ of its equilibrium level. This implies an amended inflation model of the form

$$
\pi_{t}=\alpha \pi_{t-1}+(1-\alpha) E \pi_{t+1}+\beta \tilde{m}_{t-1}+\varepsilon_{\pi, t} .
$$

Alternatively, Reynard (2007) has interpreted $p^{*}$ as the equilibrium level of prices supported by the current quantity of money in circulation, given potential output, $y_{t}^{*}$, and equilibrium velocity, $v_{t}^{*}$, which might include a trend. This yields

\footnotetext{
${ }^{5}$ Equation $\left(1_{\mathrm{P}^{*}}\right)$ combines a number of approaches. Hallman and others (1991), for instance, assume $\alpha=1$, which seems to be in line with Reynard's (2007) empirical observation that the price gap influences inflation with considerable lags and some persistence. As a rule, the $\mathrm{P}^{*}$ model does not restrict the expectations term, which, in principle, could take any form.
} 


$$
\pi_{t}=c+\alpha \pi_{t-1}+(1-\alpha) E \pi_{t+1}+\beta\left(m_{t-1}^{*}+v_{t-1}^{*}-y_{t-1}^{*}\right)+\varepsilon_{\pi, t},
$$

with $c>0$.

\section{Empirical Models}

In addition to theory-guided approaches, practitioners often rely on purely empirical models of inflation (Fischer and others 2008). Two broad classes of empirical models, time series and cross-section, seem to be particularly interesting to assess the information content of money for inflation.

\section{Time series models}

One of the simplest time series model for forecasting inflation is the univariate autoregressive model (AR), which relates current inflation to a constant and its own lags:

$$
\pi_{t}=c+\rho(L) \pi_{t}+\varepsilon_{\pi, t}+\theta(L) \varepsilon_{\pi, t},
$$

where $\rho(L)$ are lag polynomial autoregressive and $\theta(L)$ lag moving average coefficients. The question is again, whether adding monetary information can improve this model in its ability to forecast inflation.

One straightforward extension of equation $\left(1_{\mathrm{TS}}\right)$ is a bivariate autoregressive distributed lag model (ARDL), which adds lags of money growth,

$$
\pi_{t}=c+\rho(L) \pi_{t}+\alpha(L) \Delta M_{t}+\varepsilon_{\pi, t}+\theta(L) \varepsilon_{\pi, t},
$$

where $\alpha(L)$ are lag polynomial coefficients capturing the effects of nominal money growth. An important difference between $\left(1_{\mathrm{TS}}\right)$ and $\left(2_{\mathrm{TS}}\right)$ is that the AR model provides an unconditional dynamic forecast of inflation, while forecasts based on the ARDL model will be conditional on money growth - which will have to be forecasted outside the model, for instance using an AR approach.

To ensure against bias in the comparison of the conditional and unconditional forecasts of inflation, it is useful to also consider a bivariate vector-autoregressive (VAR) model of inflation and money,

$$
\left[\begin{array}{c}
\pi_{t} \\
\Delta M_{t}
\end{array}\right]=\sum_{j} A_{j}\left[\begin{array}{c}
\pi_{t-j} \\
\Delta M_{t-j}
\end{array}\right]+\left[\begin{array}{c}
\varepsilon_{\pi, t} \\
\varepsilon_{\Delta M, t}
\end{array}\right],
$$

where $A$ is a matrix of reduced form coefficients, $j$ is the number of lags, and $\varepsilon_{\pi, t}$ and $\varepsilon_{\mu, t}$ are independently identically normally distributed (iid) residuals. Berger and Österholm (2008a, 2008b) demonstrate that this framework can be used for comparing the accuracy of inflation models with and without money. 


\section{Generalized dynamic factor models}

An alternative empirical framework are GDFM, which have been successfully employed to forecast inflation with large cross-section of data (Stock and Watson 1999, Forni and others 2003). The main idea is that the information content of a large set of variables can be represented by a smaller set of indicators, so-called common factors in a dynamic setting. As a result, a composite indicator can be constructed to forecast inflation. Specifically

$$
x_{i, t}=\lambda_{1, i} f_{1, t}+\ldots+\lambda_{p, i} f_{q, t}+x_{i, t}^{i}=x_{i, t}^{c}+x_{i, t}^{i},
$$

where, $x_{i, t}$, with $i=1, . ., n$, is a set of variables that, in addition to inflation, includes, for instance, other price variables, indicators of real activity, or financial variables. In addition, $x_{i, t}$ may or may not include monetary information. Furthermore, the $f_{j, t}$, with $j=1, . ., q$, are common factors affecting all variables, $\lambda_{k, i}$, with $k=1, . ., p$ are variable-specific loading factors, $x_{i, t}^{c}$ is the common component of $x_{i, t}$, which is driven by the common shocks to all data, while $x_{i, t}^{i}$ is the idiosyncratic component, which is driven by pervasive shocks. The two components are identified by assuming that they are orthogonal.

The approach can be applied to the task at hand by contrasting the ability of the GDFM approach to model inflation when $x_{i, t}$ is restricted to exclude money with the results when it includes money.

\section{EMPIRICAL Methods ANd DATA}

The models discussed in Section III, with some modifications, can be taken to the data and used to forecast inflation. In what follows, we describe the adjustments made in the actual empirical implementation (also see Appendix I).

\section{A. Estimation Techniques}

We apply several estimation techniques, depending on the complexity of the relevant class of models. For the DSGE and the $\mathrm{P}^{*}$ models, which have a large number of parameters, we use a Bayesian approach. The key advantage of this technique is that it allows a more precise inference, as the information content is broadened beyond the estimation sample by using prior distributions. The more traditional reduced-form Phillips curve models and the time series models, which are less parameter intensive, are estimated by OLS. Lastly, for the large cross-section data set, we apply modern generalized dynamic factor techniques, which improve statistical inference compared to traditional panel methods.

Wherever feasible, we estimated unobservable variables such as potential output in a model-consistent way using a Kalman filter approach. One exception is the real money gap in the DSGE models, which, for various technical reasons, was approximated using an off-model 
Hodrick-Prescott filter. The ex-post real interest rate is calculated by subtracting the actual next period inflation rate from the nominal interest rate.

In general, the empirical equations of the DSGE models follow the theoretical specifications discussed in the theoretical part. ${ }^{6}$ However, we introduce the lagged output gap as an additional right-hand-side variable in the aggregate demand equations in the standard NKM model as well as in the generalized NKM model with intra-period non-separability to ensure that the dynamic response of the models is better aligned with the data. ${ }^{7}$

\section{B. Prior Distribution of Parameters for the Bayesian Estimates}

To set the parameters for the prior distribution of the coefficients for the DSGE models, we use the estimates provided in Smets and Wouters $(2003,2004)$ and our own single equation OLS estimates. The priors for the $\mathrm{P}^{*}$ models are based on OLS estimates of the parameters. Tables A2.1 and A2.2 in Appendix II provide the specifics. In what follows, we highlight some of the more important assumptions regarding the priors.

An important parameter for the dynamic properties of the DSGE and P* models is the degree of inflation inertia. Focusing first on the DSGE model, we experimented with two values of the share of backward-looking economic agents in the aggregate supply equation $-\theta_{\pi}=0.75$ (high inflation inertia), and $\theta_{\pi}=0.25$ (low inflation inertia), with quite tight priors in both cases (see Table A2.1). We evaluated their fit based on the ratio of the exponentials of the marginal data density of the models, which represents the relative probabilities of the models being consistent with the historical data. For the euro area, this odds ratio suggests that a Phillips curve with less forward-looking agents fits the data better. For consistency reasons, the same prior is then used for the $\mathrm{P}^{*}$ model, (i.e. $\alpha=0.75$ ).

For both classes of models, the priors for the coefficients of the money demand equations are based on OLS estimates by using relatively diffuse priors (see Table A2.2). Another important decision regarding DSGE models concerns the coefficients in the Taylor-type monetary policy rule. Here we follow Smets and Wouters (2003) without enforcing tight priors, except for the coefficient for money, which is based on OLS estimates.

\section{Forecasting and the Information Content of Money}

To assess the information content of money for inflation, we compare the out-of-sample forecasting performance of the models with and without money discussed above. This is akin to the Granger-causality test suggested by Ashley and others (1980). If money does contain information relevant for the level and/or dynamics of inflation in the euro area, we would expect

\footnotetext{
${ }^{6}$ Note that the coefficients estimated for the DSGE models are semi-structural, as we do not enforce some of the restrictions implied by the deep parameters of the underlying model in the empirical implementation.

${ }^{7}$ More specifically, the assumption of no inertia in aggregate demand is rejected by the data despite tight Bayesian priors.
} 
money-based models to deliver better out-of-sample inflation forecasts. This comparison is particularly meaningful for nested models, that is, within the various model classes discussed in Section III. However, it can also be instructive to compare forecasting accuracy across model classes.

To compare forecasting accuracy, we use the root mean square error of forecasts (RMSE). RMSEs provide a direct measure of the size of forecast errors. If $h$ is the relevant forecasting horizon, the RMSE is defined as

$$
R M S E_{h}=\sqrt{\sum\left(\pi_{t+h}-\tilde{\pi}_{t+h}\right)^{2} / T},
$$

where the $\tilde{\pi}_{t}$ is the inflation forecast generated by a particular model and $T$ is the number of observations.

The forecasts themselves are generated as follows. For the simulated out-of-sample forecasts, we estimate all models for an initial training period 1993Q1 to 1999Q4 and run forecasting exercises at horizons of one, four, eight, and twelve quarters ahead starting in 2000Q1. Then the forecasting window is moved by one quarter, and new forecasts at all horizons are computed. As a rule, we do not allow the model coefficients to update during after the training period. The exception are the two model classes that incorporate conditional forecasting models depending on off-model information. This includes the class of Phillips curve models (where all models are conditional) and the class of times series models (where the bi-variate single-equation times series model is conditional on M3 growth). Since we update the conditioning off-model information each period during the evaluation sample, we opted to update the forecasting equation as well for consistency reasons. ${ }^{8}$

\section{Data}

We use official aggregate euro area data taken from the ECB and Eurostat websites, complemented where necessary with the corresponding series from the Area Wide Model. The data frequency is quarterly and the full sample runs from the first quarter of 1993 to the second quarter of $2007 .^{9}$

\footnotetext{
${ }^{8}$ Note that the within-model class comparison is not affected by this convention. To forecast the off-model conditional variables - in particular, the output and real money gaps and long-term money growth for the Phillips curve models, and money growth for the ARDL model - we proceed in two steps. For a given forecasting window, we first calculate these variables using a standard Hodrick-Prescott filter and then forecast them up to twelve quarters ahead using an ARMA process. This process is repeated each time the forecasting window is moved and a new observation is added.

${ }^{9}$ The fact that our simulated out-of-sample exercise is based on revised instead of real time data should have no bearing on the results. A bias (if any) in forecasting accuracy that the use of revised data may create would influence all models simultaneously, leaving their relative performance unchanged. And indeed, in a recent paper, Faust and Wright (2007) show that the use of real time or revised data does not influence the relative performance of various model- and expert-based forecasts for inflation and output in the U.S. economy.
} 
For the theoretical and time-series models, the following variables in levels are used: real GDP, the CPI index, nominal M3, and the 3-month T-bill interest rate. For the GDFM models, in addition, we use the following series for each euro area member state: nominal M1 and M2, unemployment, unit labor costs, wages, the HICP index, the 10-year government bond yield, and industrial production. With the exception of the interest rates, all series are in logs and seasonally adjusted. Real money stocks are obtained using the CPI index. Quarterly growth rates for real GDP, CPI, and monetary aggregates are defined as the annualized quarterly or annual percent change of these variables.

\section{Results}

We present the results along a number of dimensions. First, we look at the marginal contribution of money within each class of nested models. Second, we assess its role in inflation forecast performance across all models incorporating money. And, finally, we discuss the forecasting performance of all models.

\section{A. The Marginal Contribution of Money}

Figure 1 describes the performance of the various DSGE models discussed in Section III, depicting the out-of-sample RMSEs at forecasting horizons of one, four, eight, and twelve quarters ahead. A lower RMSE implies better forecasting accuracy at a particular horizon. ${ }^{10}$

Figure 1. Forecast Performance of DSGE Models

(RMSE of dynamic forecasts, in percentage points of year-on-year inflation)

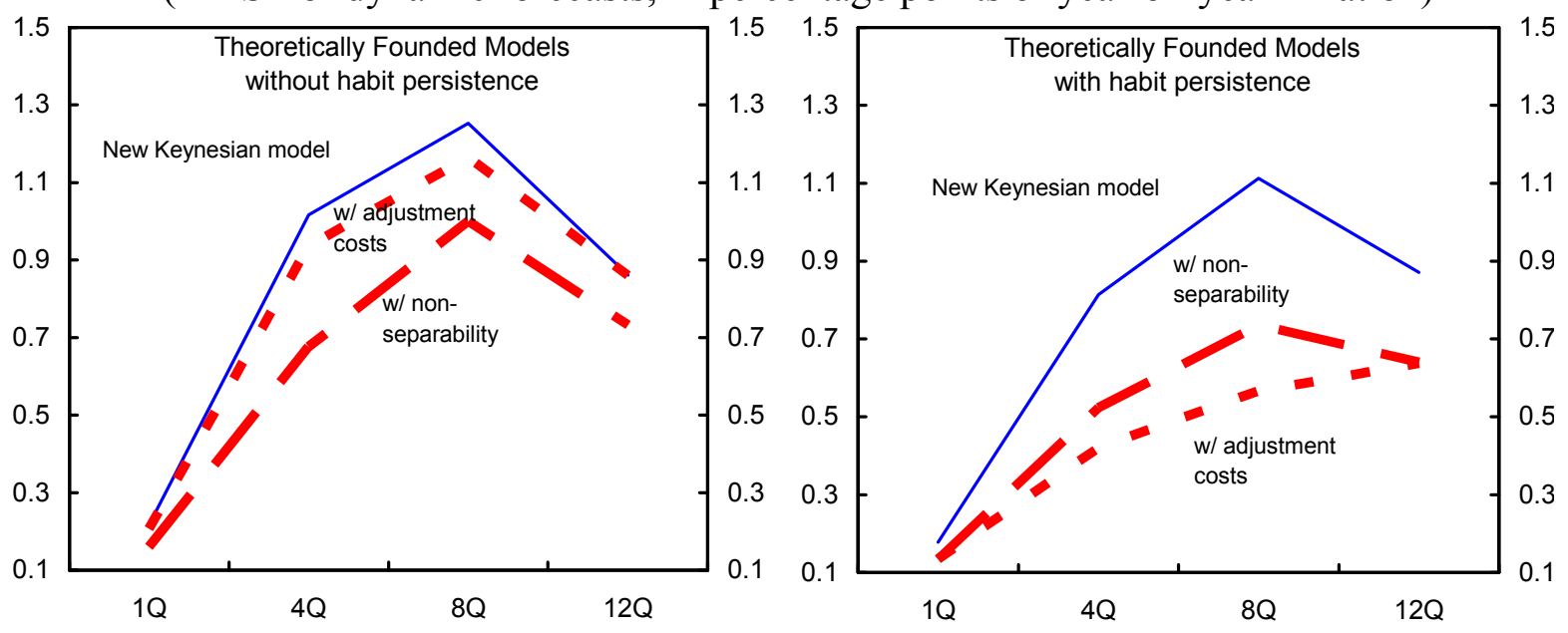

The results suggest that the generalized NKM approaches that, one way or the other, incorporate money balances perform well compared to the cashless NKM baseline (Figure 1). The

\footnotetext{
${ }^{10}$ Table 1 further below, in addition, shows the relative rank of the models within each nested model class (see columns named "within model class") based on the relative RMSE at the twelve quarter horizon and the average RMSE across all horizons, respectively.
} 
introduction of habit persistence, while improving the forecasting performance of the DSGE models overall, does not alter this result. The main difference between the right and the left panel is that the adjustment-cost model delivers the best forecasting performance in the case of NKM models with habit persistence, while the non-separability model shows the lowest RMSE of the NKM models without habit persistence.

The size of the improvements in forecasting accuracy from adding money varies with the time horizon but is limited on average. For example, at the two-year horizon, for the NKM without habit persistence, moving from the cashless baseline NKM model to a model with non-separability reduces the RMSE by as much as 0.25 percentage points, while for the NKM with habit persistence moving from the baseline to the model with adjustment costs lowers the RMSE by almost 0.55 percentage points of inflation. ${ }^{11}$ However, at 0.2 and 0.3 percentage points, respectively, the improvements across all forecasting horizons are smaller. Nevertheless, these results seem to contradict Woodford's $(2003,2006)$ argument that there is no role for money in inflation determination in the NKM approach and are broadly in line with Andrés and others (2007), who claim that a NKM incorporating money provides a good empirical description the euro-area economy.

An additional result from the DSGE models with non-separability is that money affects inflation mainly through improving the empirical specification of the aggregate demand and aggregate supply equations, while the effect from monetary policy reaction to money balances is small. We checked the importance of the monetary policy channel by comparing the out-of-sample forecasting performance of the model with and without money and found very similar differences in the implied RMSEs. ${ }^{12}$

Figure 2. Forecast Performance of Empirical Models (RMSE of dynamic forecasts, in percentage points of year-on-year inflation)
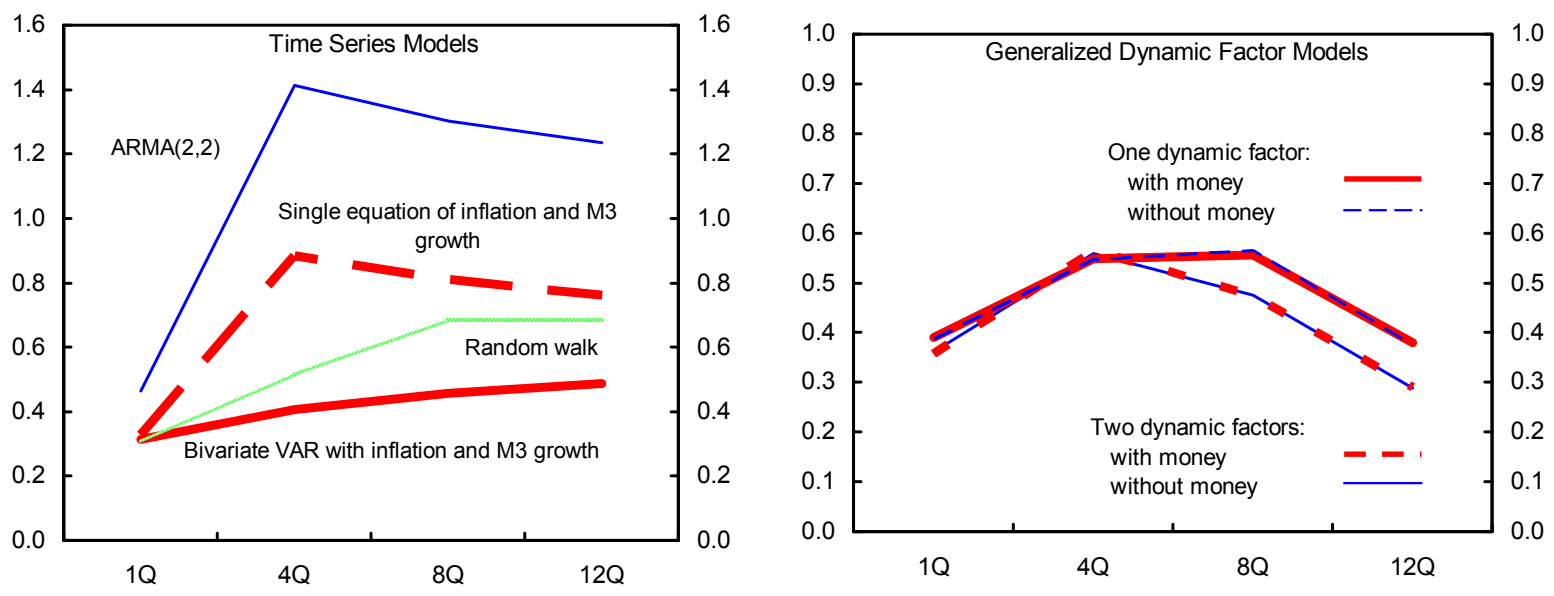

\footnotetext{
${ }^{11}$ Note that this is not simply an artifact of the NKM model lacking the ability to capture the persistence in the data, which may influence forecasting accuracy. In the empirical implementation, all estimated equations include lagged endogenous variables (see Section III and Appendix I).

${ }^{12}$ Additional results available on request.
} 
From general equilibrium models, we move to the other extreme, purely empirical models. Figure 2 presents the results in the now familiar setup. The results from the time-series models (left panel) indicate that money does improve inflation forecasting. The ARDL single equation approach containing money, while not beating the random walk model, delivers better inflation forecasts than the ARMA approach. The best time-series model in terms of RMSEs across all horizons is the bivariate VAR model. At about 0.5 to 1.0 percentage points depending on the horizon, the reduction in RMSE gained by the bivariate VAR model against the ARMA is considerable, but the improvement against the random walk model is modest at best. These results are consistent with other studies in the literature that have used time-series models. For example, Berger and Österholm (2008a), also using a Bayesian VAR approach, find that including money allows better predictions of inflation, while Fischer and others (2008) show that bivariate monetary forecasts bring new information to the broad macroeconomic projections.

The results from the GDFM models, however, do not suggest that incorporating monetary indicators appreciably improves inflation forecasting performance once a broader set of economic indicators is taken into account (Figure 2, right panel). While the GDFM model with two factors including various monetary indicators does better in forecasting inflation than the two-factor model without money, the reduction in RMSEs is miniscule. Turning to the one-factor GDFM models, we find that the opposite holds: the model without money outperforms the one-factor model with money, even though the differences in RMSE levels remain very small in this case as well. This result seems to run against Hofmann (2006), who reports that factor models with money do consistently better than factor models without money in forecasting inflation over the twelve-quarter horizon.

Figure 3. Forecast Performance of $\mathrm{P}^{*}$ and Phillips Curve Models (RMSE of dynamic forecasts, in percentage points of year-on-year inflation)
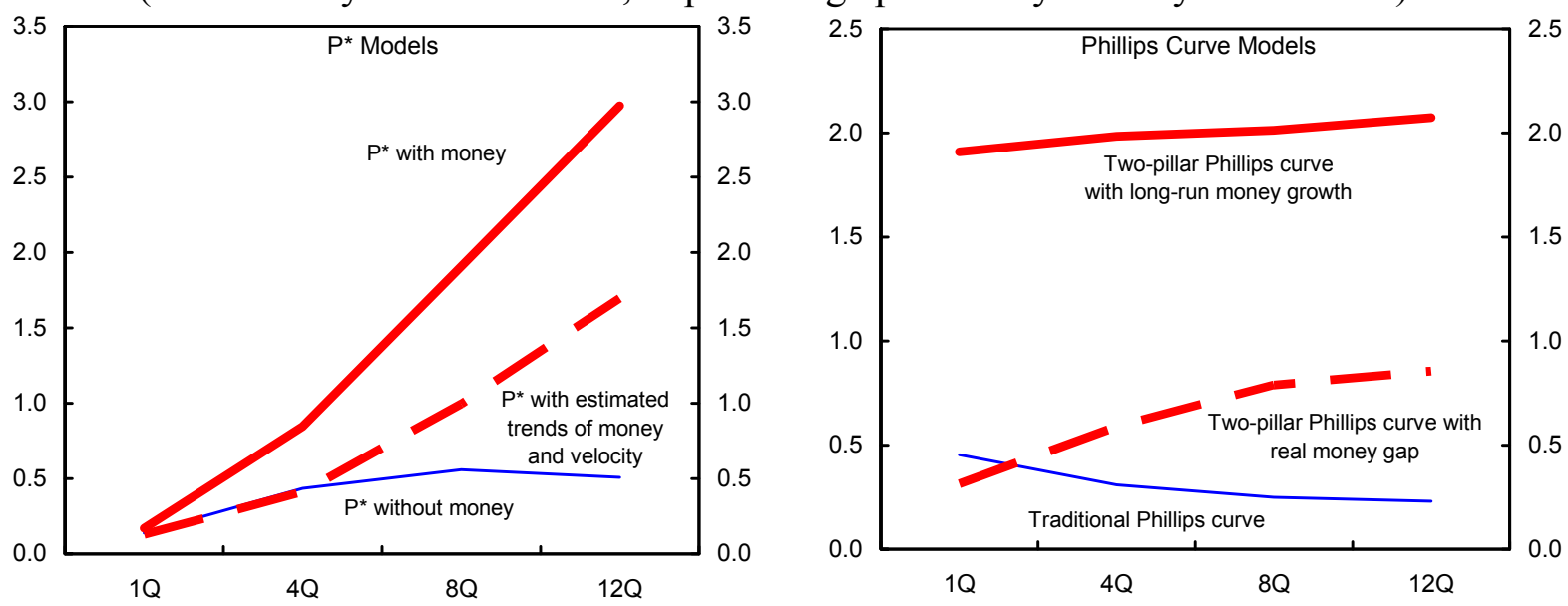

Finally, we consider partial equilibrium models. Other than the results from the DSGE and empirical models, the outcome from the partial equilibrium models imply no role for money (Figure 3). More specifically, the simplest $\mathrm{P}^{*}$ model with no money has the best forecast performance in this class of models, with the two models with money lagging far behind (left panel). Similarly, we find that among the reduced-form Phillips curve models, the standard formulation excluding money produces the best forecast among this group of models at longer 
horizons, with the two-pillar Phillips curves, and, in particular, the one with long-term money growth, faring much worse.

The relatively weak performance of the money-based $\mathrm{P}^{*}$ and two-pillar Phillips curve models, two approaches that are used widely by forecasting practitioners, runs across some of the recent contributions in the literature (see Section II). The results for the P* models are surprising, given that we estimate the trend of money balances in a model-consistent way, which, in principle, delivers better forecasting performance than single equation filters, such as a HodrickPrescott filter. One possible explanation could be parameter uncertainty with regard to the money demand function. A factor relevant for the two-pillar Phillips approach may be the choice of the filter used to identify long-run movements in the data, where AssenmacherWesche and Gerlach (2006a, 2006b) apply fairly sophisticated frequency-based techniques.

\section{B. Comparison of Money-Based Models}

We now turn to comparing forecasting performance of money models (see Table 1). An obvious disadvantage of this perspective is that this involves contrasting non-nested models, but it still seems interesting to learn about the relative performance of the various money-based approaches in unified empirical setting. Table 1 presents the results in the columns dubbed "within money models", which report the relative rank of all relevant models based on the RMSE for the twelve-quarter ahead forecasts and the average RMSE across all horizons, respectively.

There are some surprising results. For example, DSGE money models, which are not necessarily known for their good overall forecasting performance, fare fairly well among money models. Out of twelve money based models overall, the best generalized NKM approach ranks third. It is also interesting to note that the two-pillar Phillips curve with real money gap also scores relatively high (rank six), supporting results in Gerlach and Svensson (2003). The best relative forecasting performance, however, comes from the bivariate VAR model, followed by the factor models containing monetary information (ranks one and two). Partial equilibrium approaches perform worst.

One implication of the relative performance of the money based models is the seemingly "u-shaped" relationship between the degree of their theoretical underpinnings and their forecasting accuracy. The best empirical model and the best DSGE model are doing better than best partial equilibrium model. A corollary of this is that, from a forecasting standpoint, the information content of money is not necessarily adequately captured by partial equilibrium models - instead, a more explicit modeling of the dynamics and underlying theoretical structure of the money-inflation relationship seem to be called for.

\section{Comparison Across All Models}

Finally, we compare forecast performance across all models. While this again involves comparing non-nested models, the practice is common in the literature. The relevant rankings are displayed in the columns named "overall" in Table 1. Strikingly, the best performing model is an approach without money - the traditional Phillips curve. This holds both at the horizon of 
twelve quarters and for the average performance over all forecasting horizons. At about 0.1 percentage points of inflation, the difference to the runner-up monetary models is not overwhelming, however. For most models the overall ranking does not change substantially whether the assessment is done over all horizons or based on the twelve quarter forecast. But

Table 1. Out-of-sample Forecasting Performance of Models (RMSE of year-on-year inflation forecasts, in percentage points)

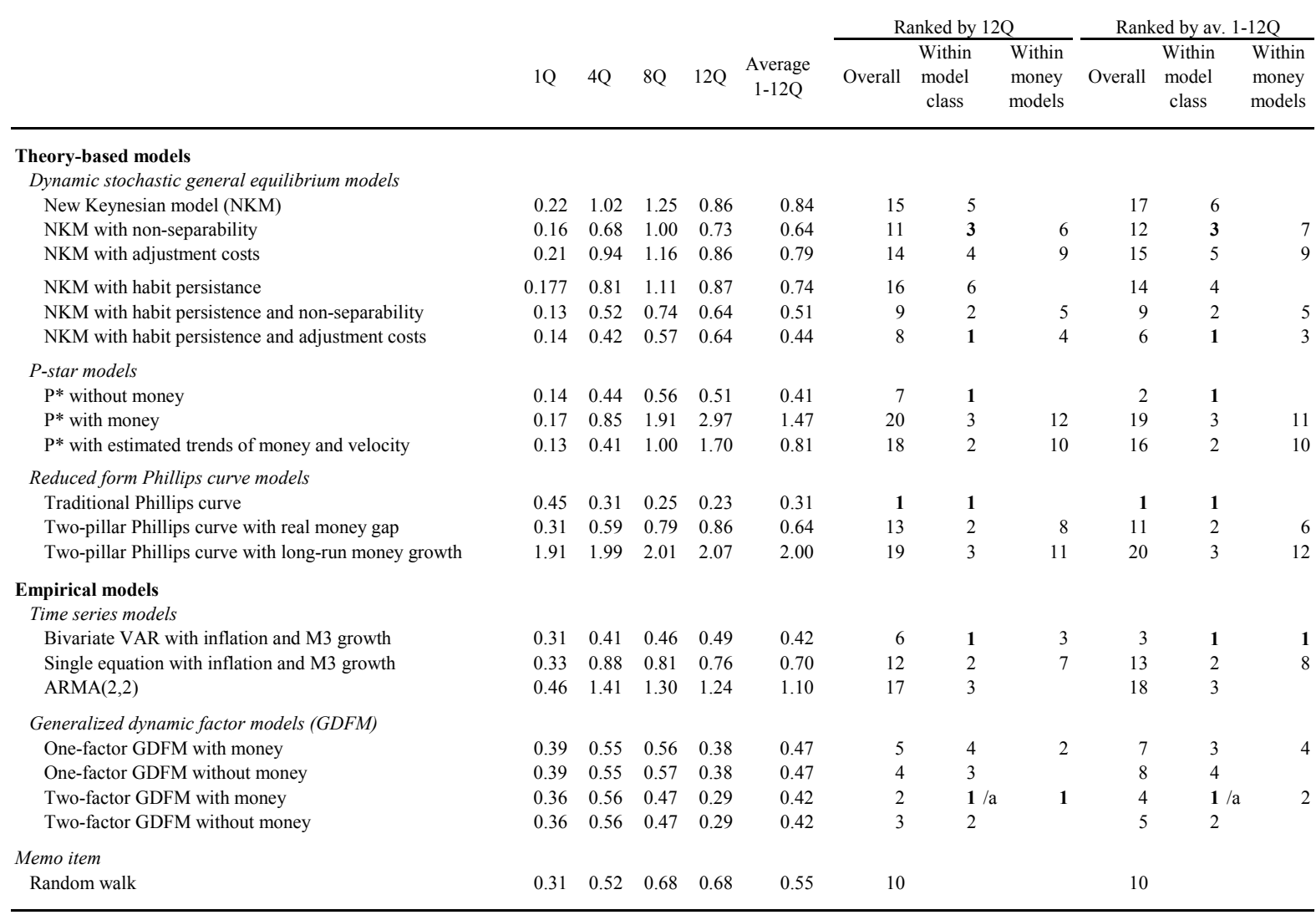

a/ The two factor GDFM model with money shows an improvement over GDFM model without money at the third decimal point.

note that the GDFM approaches with and without money do best at longer horizons, while the $\mathrm{P}^{*}$ model class, which does not perform well overall, does better than most at very short horizons.

Overall, these results warn against overestimating the contribution of money to the accuracy of inflation forecasting out-of-sample. While some money-based approaches do very well within their particular class of theoretical or empirical models, all are dominated by models excluding money in all-out the horserace. ${ }^{13}$

\footnotetext{
${ }^{13}$ In part, this might be explained by the fact that our approach emphasizes within-class comparisons, and that we have made no effort to fine-tune the performance of a particular class of model vis-à-vis another. On the other hand, it is not immediately obvious how such an effort would alter the results.
} 


\section{Conclusions}

This paper contributes to the debate on the role of money in monetary policy by analyzing the information content of money in forecasting inflation in the euro area. Our approach is to compare the predictive performance within a range of structural and empirical model classes. All models are estimated over the same initial training period, 1993 to 1999, and their inflation forecasting performance is assessed in a simulated out-of-sample exercise for the period 2000 to 2007.

We find that money contains relevant information for inflation. For instance, New Keynesian DSGE approaches incorporating money balances and money-based VAR models perform better in forecasting inflation than their cashless counterparts.

In addition, the comparison of the forecasting performance of money-based models points at a "u-shaped" relation between theoretical underpinnings and the prediction accuracy of these models: the best money-based VAR and DSGE models dominate the best partial equilibrium $\mathrm{P}^{*}$ or two-pillar Phillips curve models. This seems to suggest that the information content of money is best captured by explicitly modeling the dynamics and underlying theoretical structure of the money-inflation relationship.

But there are also signs that the contribution of money to the accuracy of inflation forecasting out-of-sample has its limits. First, we do not find that including monetary information aids forecasting accuracy within the class of modern dynamic factor models (here the contribution is miniscule) and, surprisingly perhaps, partial equilibrium models (where it seems to be even negative). Second, we find that, across models overall, non-monetary approaches provide better inflation forecasts than money-based models. While the differences in RMSEs are not too large, this results cautions against overemphasizing the role of monetary information in inflation forecasting. 


\section{REFERENCES}

Andrés, Javier, David López-Salido, and Javier Vallés (2006), Money in an Estimated Business Cycle Model of the Euro Area, Economic Journal, 116, 457-77.

Aoki, Kosuke (2006), Optimal Commitment Policy under Noisy Information, Journal of Economic Dynamics and Control, 30(1) 81-109.

Andrés, Javier, David Lopez-Salido, and Edward Nelson (2007), Money and the Natural Rate of Interest: Structural Estimates for the UK, the US and the Euro Area, Research Division Federal Reserve Bank of St. Louis Working Paper Series, 2007-05A.

Ashley, R., Clive W.J. Granger Granger, and Richar Schmalensee (1980), Advertising and Aggregate Consumption: An Analysis of Causality Econometrica 48: 1149-67.

Assenmacher-Wesche, Katrin and Stefan Gerlach (2006a), Interpreting Euro Area Inflation at High and Low Frequencies, BIS Working Paper, 195.

Assenmacher-Wesche, Katrin and Stefan Gerlach (2006b), Understanding the Link between Money Growth and Inflation in the Euro Area, Manuscript, February.

Assenmacher-Wesche, Katrin, Stefan Gerlach, and Toshitaka Sekine (2007), Monetary Factors and Inflation in Japan, Manuscript, January.

Berger, Helge, and Pär Österholm (2008a), Does Money Growth Granger-Cause Inflation in the Euro Area? Evidence from Out-of-Sample Forecasts Using Bayesian VARs, IMF Working Papers, WP/08/53.

Berger, Helge and Pär Österholm (2008b), Does Money Matter for U.S. Inflation? Evidence from Bayesian VARs, IMF Working Papers, WP/08/76.

Bernanke, Ben, Mark Gertler, and Simon Gilchrist (1996), The Financial Accelerator in a Quantitative Business Cycle Framework, Review of Economics and Statistics, 78(1), 1-15.

Bundesbank, Deutsche (2005), The Relationship Between Money and Prices, Monthly Report, January, 13-24.

Christiano, Lawrence, Martin Eichenbaum, and Charles Evans (2005), Nominal Rigidities and the Dynamic Effects of a Shock to Monetary Policy, Journal of Political Economy, 113(1), $1-45$.

D’Agostino, Antonello, Domenico Giannone, and Paolo Surico (2006), (Un)Predictability and Macroeconomic Stability, ECB Working Paper, 605.

De Grauwe, Paul and Magdalena Polan (2005), Is Inflation Always and Everywhere a Monetary Phenomenon? Scandinavian Journal of Economics, 107(2), 239-59.

Diamond, Douglas and Raghuram Rajan (2006), Money in a Thory of Banking, American Economic Review, 96(1), 30-53. 
Forni, Mario, Marc Hallin, Marco Lippi, and Lucrezia Reichlin, (2003), Do Financial Variables Help Forecasting Inflation and Real Activity in the Euro Area?, Journal of Monetary Economics, 50, 1243-55.

Faust, Jon and Jonathan Wright (2007), Comparing Greenbook and Reduced Form Forecasts Using a Large Realtime Dataset, NBER Working Paper, 13397.

Fischer, Björn, Michele Lenza, Huw Pill, and Lucrezia Reichlin (2008) Money and Monetary Policy: The ECB Experience 1999-2006, in: Andreas Beyer and Lucrezia Reichlin (eds.), The Role of Money-Money and Monetary Policy in the Twenty-First Century, Proceedings of the Forth ECB Central Banking Conference 9-10 November 2006, ECB: Frankfurt, $102-175$.

Fuhrer, Jeffrey (2000), Habit Formation in Consumption and Its Implications for Monetary-Policy Models, American Economic Review, 90(3), 367-90.

Galí, Jordi, Stefan Gerlach, Julio Rotemberg, Harald Uhlig, and Michael Woodford (2004), The Monetary Policy Strategy of the ECB Reconsidered, Monitoring the European Central Bank No. 5, CEPR: London.

Gerlach, Stefan (2004), The Two Pillars of the European Central Bank, Economic Policy, 40, October, 389-439.

Gerlach, Stefan and Lars Svensson (2003), Money and Inflation in the Euro Area: A Case for Monetary Indicators? Journal of Monetary Economics, 50(8), 1649-72.

Hale, Galina, and Òscar Jordà (2007), Do Monetary Aggregates Help Forecast Inflation?, FRBSF Economic Letter.

Hallman, Jeffrey, Richard Porter, and David Small (1991), Is the Price Level Tied to the M2 Monetary Aggregate in the Long Run? The American Economic Review, 81(4), 841-58.

Hofmann, Boris (2006), Do monetary indicators (still) predict euro area inflation? Deutsche Bank Discussion Paper No. 18.

Kugler, Peter, and Sylvia Kaufmann (2005) Does Money Matter for Inflation in the Euro Area?, Austrian National Bank WP No. 103.

McCallum, Bennett (2001) Monetary Policy Analysis in Models without Money, NBER Working Paper, 8174.

Nelson, Edward (2002), Direct Effects of Base Money on Aggregate Demand: Theory and Evidence, Journal of Monetary Economics, 49(4), 687-708.

Nelson, Edward (2003), The Future of Monetary Aggregates in Monetary Policy Analysis, Journal of Monetary Economics, 50(5), 1029-59. 
Nicoletti-Altimari, Sergio (2001) Does Money Lead Inflation in the Euro Area?, ECB Working paper, No. 63.

OECD, (2007), Economic Survey of the Euro Area 2007: The Role of Monetary Aggregates in Monetary Policy, OECD: Paris.

Rudebusch, Glenn and Lars Svensson (2002), Eurosystem Monetary Targeting: Lessons From US. Data, European Economic Review, 46(3), 417-42.

Reynard, Samuel (2007), Maintaining Low Inflation, Money, Interest Rates, and Policy Stance, Journal of Monetary Economics, 54(5), 1441-71.

Roffia, Barbara and Andrea Zaghini (2007), Excess Money Growth and Inflation Dynamics, ECB Working Paper, 749.

Scharnagl, Michael and Christian Schumacher (2007), Reconsidering the Role of Monetary Indicators for Euro Area Inflation from a Bayesian Perspective Using Group Inclusion Probabilities, Deutsche Bundesbank Discussion Paper, 09/2007.

Smets, Frank, and Raf Wouters, (2003), An Estimated Dynamic Stochastic General Equilibrium Model of the Euro Area, Journal of the European Economic Association 1(5), September 2003, 1123-75.

Smets, Frank and Raf Wouters (2004), Forecasting with a Bayesian DSGE Model: an Application to the Euro Area, ECB Working Paper Series, No. 389.

Stavrev, Emil (2006), Measures of Underlying Inflation in the Euro Area: Assessment and Role for Informing Monetary Policy, IMF Working Papers, WP197.

Stock, James H., and Mark. W. Watson (1999), "Forecasting Inflation,” Journal of Monetary Economics, 44, 293-335.

Svensson, Lars (2000), Does the P* Model Provide Any Rationale for Monetary Targeting? German Economic Review, 1, 69-81.

Woodford, Michael (2003), Interest and Prices: Foundations of a Theory of Monetary Policy, Princeton University Press: Princeton.

Woodford, Michael (2006), How Important is Money in the Conduct of Monetary Policy? Queen's Economics Department Working Paper No. 1104.

Woodford, Michael (2008), Does a "Two-Pillar Phillips Curve” Justify a Two-Pillar Monetary Policy Strategy? in: Andreas Beyer and Lucrezia Reichlin (eds.), The Role of Money-Money and Monetary Policy in the Twenty-First Century, Proceedings of the Forth ECB Central Banking Conference 9-10 November 2006, ECB: Frankfurt, 56-82. 


\section{APPENDIX I: EMPIRICAL SPECIFICATIONS}

In this appendix we discuss the empirical specifications used to estimate the DSGE (or NKM) and $\mathrm{P}^{*}$ models. All variables in the appendix are defined in levels. ${ }^{14}$

\section{The cashless New Keynesian Model}

Phillips curve

$$
\pi_{t}=\theta_{\pi} \pi_{4, t-1}+\theta_{E \pi} E \pi_{4, t+1}+\theta_{x_{t}} x_{t}+\varepsilon_{\pi, t}
$$

where, $\pi_{t}$ is quarterly seasonally adjusted inflation at an annual rate, $\pi_{4, t-1}$ is year on year inflation, $E$, is the expectation operator based on the information available as of time $t, x_{t}$ is output gap (defined below), and $\varepsilon_{\pi, t}$ is an error term that captures supply shocks. Note that the following restriction on lagged and expected inflation is imposed, $\theta_{\pi}=1-\theta_{E \pi}$ and annual inflation is defined as the backward moving average of quarterly inflation, $\pi_{4, t}=\left(\pi_{t-3}+\pi_{t-2}+\pi_{t-1}+\pi_{t}\right) / 4$.

Aggregate demand

$$
x_{t}=\phi_{x_{t-1}} x_{t-1}+\phi_{E x_{t+1}} E x_{t+1}-\phi_{i}\left(i_{t}-E \pi_{4, t+1}-r_{t}^{n}\right)+\varepsilon_{x, t}
$$

where, $i$ is the nominal interest rate, $r_{t}^{n}$ is the real natural interest rate, and $\varepsilon_{x, t}$ is an error term that captures demand shocks. Note that we deviate here from the theoretical aggregate demand curve described in Section III.A by adding the lagged output gap.

\section{Monetary policy reaction function}

$$
i_{t}=\rho_{i} i_{t-1}+\left(1-\rho_{i}\right)\left[r_{t}^{n}+\pi_{4, t+4}+\kappa_{E \pi_{t+1}}\left(\pi_{4, t+4}-\pi^{*}\right)+\kappa_{x_{t}} x_{t}\right]+\varepsilon_{i, t}
$$

Where $x_{t}$ is defined as the difference between the log of real GDP $y_{t}$ and its equilibrium level $\bar{y}_{t}$ (defined below), $i_{t}$ is the nominal interest rate, $\pi^{*}$ is the central bank's inflation target, and $\varepsilon_{i, t}$ is an error term that captures monetary policy shocks.

In addition to the above main equations, we also add several equations to estimate the modelconsistent equilibrium output, long-term real GDP growth, and real interest rate.

\section{Equilibrium output}

$$
\bar{y}_{t}=\bar{y}_{t-1}+\frac{g_{t}}{4}+\varepsilon_{\bar{y}, t}
$$

where, $\bar{y}_{t}$ is log of the level of equilibrium real GDP, $g_{t}$ is the quarterly real GDP growth at annual rate, and $\varepsilon_{\bar{y}, t}$ is a shock to equilibrium output.

\footnotetext{
${ }^{14}$ In general, we follow the notation of the main text. For ease of exposition, we use Roman letters to abbreviate growth rates where required.
} 
GDP growth

$$
g_{t}=\tau g^{*}+(1-\tau) g_{t-1}+\varepsilon_{g_{t}, t}
$$

where $g^{*}$ is steady state real GDP growth and $\varepsilon_{g}$ is a shock to steady state growth.

Real natural interest rate

$$
r_{t}^{n}=\rho r^{*}+(1-\rho) r_{t-1}^{n}+\varepsilon_{r_{t}^{n}, t}
$$

where, $r^{*}$ is steady state real interest rate and $\varepsilon_{r_{i}^{n}, t}$ is a shock to equilibrium real interest rates.

The above system of equations, (A1)-(A6), is used to estimate the cashless NKM.

\section{Adjustment costs}

In the case of the NKM with adjustment costs, the aggregate supply and the aggregate demand equations remain as specified in (A1) and (A2) above. The money demand equation takes the form,

$$
m_{t}=\bar{\gamma}_{y_{t}} y_{t}-\bar{\gamma}_{i} i_{t}+\bar{\gamma}_{m_{t-1}} m_{t-1}+\bar{\gamma}_{E m} E m_{t+1}+\varepsilon_{m, t},
$$

where $m_{t}$ is real money gap, defined as the percent difference of real money balances from their Hodrick-Prescott (HP) filtered trend. The monetary policy reaction function is defined as,

$$
i_{t}=\rho_{i} i_{t-1}+\left(1-\rho_{i}\right)\left[r_{t}^{n}+\pi_{4, t+4}+\tilde{\kappa}_{E \pi_{t+1}}\left(E \pi_{t+1}-\pi^{*}\right)+\tilde{\kappa}_{x_{t}} x_{t}+\tilde{\kappa}_{M_{t}} \bar{M}_{t}\right]+\varepsilon_{i, t},
$$

where, $\bar{M}_{t}$ is the deviation of nominal balances from their steady state, computed using $m_{t}, \pi_{t}$, and $\pi^{*}$.

To estimate the NKM with adjustment costs, we replace equation (A3) with equation (A8) and add equation (A7) to the rest of the system to obtain the following system of equations (A1), (A2), (A8), (A4)-(A7).

\section{Non-separability}

In the case of the NKM with non-separability, the monetary policy reaction function is as in the NKM model with adjustment costs, equation (A8). The Phillips curve and the aggregate demand equations are described below.

\section{Phillips curve}

$$
\pi_{t}=\tilde{\theta}_{\pi} \pi_{4, t-1}+\tilde{\theta}_{E \pi} E \pi_{4, t+1}+\tilde{\theta}_{x_{t}} x_{t}-\tilde{\theta}_{m} m_{t}+\varepsilon_{\pi, t}
$$

Again, as in the standard NKM, the sum of the coefficients on lagged and expected inflation is one. 
Aggregate demand

$$
x_{t}=\tilde{\phi}_{x_{t-1}} E x_{t-1}+\tilde{\phi}_{E x_{t+1}} x_{t+1}-\tilde{\phi}_{i}\left(i_{t}-E \pi_{t+1}\right)+\tilde{\phi}_{m} m_{t}-\tilde{\phi}_{E m_{t+1}} E m_{t+1}+\varepsilon_{x, t}
$$

The money demand function is defined as,

$$
m_{t}=\gamma_{y_{t}} y_{t}-\gamma_{i} i_{t}+\varepsilon_{m, t}
$$

The NKM model with non-separability is estimated by replacing equations (A1) and (A2) with equations (A9) and (A10), correspondingly, and equation (A7) with equation (A11) in the system of equations used to estimate the NKM with adjustment costs, (A1), (A2), (A8), (A4)(A7). This results in the following system of equations: (A9), (A10), (A8), (A4)-(A6), and (A11).

\section{NKM with habit persistence}

In the case of NKM with habit persistence the aggregate supply, aggregate demand, and money demand equations are defined as follows:

Phillips curve

$$
\pi_{t}=\hat{\theta}_{\pi} \pi_{t-1}+\hat{\theta}_{E \pi} E \pi_{t+1}-\hat{\theta}_{x_{t-1}} x_{t-1}+\hat{\theta}_{x_{t}} x_{t}-\hat{\theta}_{E x} E x_{t+1}+\varepsilon_{\pi, t}
$$

Aggregate demand

$$
x_{t}=\hat{\phi}_{x} x_{t-1}+\hat{\phi}_{E x_{t+1}} E x_{t+1}-\hat{\phi}_{E x_{t+2}} E x_{t+2}-\hat{\phi}_{i}\left(i_{t}-E \pi_{t+1}\right)+\varepsilon_{x, t}
$$

Money demand

$$
m_{t}=\hat{\gamma}_{y_{t-1}} y_{t-1}+\hat{\gamma}_{y_{t}} y_{t}-\hat{\gamma}_{E y} E y_{t+1}-\hat{\gamma}_{i} i_{t}+\varepsilon_{m, t}
$$

The NKM with habit persistence is estimated by replacing in the system of equations for the NKM model with non-separability - (A9), (A10), (A11) - with equations (A12), (A13), and (A14), which results in the system (A12), (A13), (A8), (A4)-(A6), and (A14).

\section{NKM with habit persistence and non-separability}

In the case of NKM with habit persistence and non-separability the aggregate supply, aggregate demand, and money demand equations are defined as follows:

Phillips curve

$$
\begin{aligned}
\pi_{t}=\hat{\theta}_{\pi} \pi_{t-1}+\hat{\theta}_{E \pi} E \pi_{t+1}-\hat{\theta}_{x_{t-1}} x_{t-1}+\hat{\theta}_{x_{t}} x_{t}-\hat{\theta}_{E x} E x_{t+1} \\
-\hat{\theta}_{m} m_{t}+\hat{\theta}_{E m} E m_{t+1}+\varepsilon_{\pi, t}
\end{aligned}
$$


Aggregate demand

$$
\begin{aligned}
x_{t}=\hat{\phi}_{x} x_{t-1}+\hat{\phi}_{E x_{t+1}} E x_{t+1}-\hat{\phi}_{E x_{t+2}} E x_{t+2}-\hat{\phi}_{i}\left(i_{t}-E \pi_{t+1}\right) \\
+\hat{\phi}_{m} m_{t}-\hat{\phi}_{E m_{t+1}} E m_{t+1}+\hat{\phi}_{E m_{t+2}} E m_{t+2}+\varepsilon_{x, t}
\end{aligned}
$$

Money demand

$$
m_{t}=\hat{\gamma}_{y_{t-1}} y_{t-1}+\hat{\gamma}_{y_{t}} y_{t}-\hat{\gamma}_{E y} E y_{t+1}-\hat{\gamma}_{i} i_{t}+\hat{\gamma}_{E m} E m_{t+1}+\varepsilon_{m, t}
$$

The NKM with habit persistence and non-separability is estimated by replacing Phillips curve (A12), aggregate demand (A13), and money demand (A14) equations in the system of equations for the NKM model with habit persistence-(A12), (A13), (A8), (A4)-(A6), and (A14) - with equations (A15), (A16), and (A17), correspondingly, which results in the system (A15), (A16), (A8), (A4)-(A6), and (A17).

\section{P* model without money}

\section{Inflation equation}

$$
\pi_{t+1}=\alpha \pi_{4, t}+(1-\alpha) E \pi_{4, t+4}+\beta \tilde{p}_{t}+\varepsilon_{\pi, t}
$$

where, $\pi$ is quarterly inflation, $\pi_{4, t}$ year-on-year inflation, $E \pi_{4, t+4}$ is expected inflation (both year-on-year and expected inflation are defined as in the NKM models), and $\tilde{p}_{t}$ is the gap between the equilibrium and actual price levels.

Price gap equation

$$
\tilde{p}_{t}=p_{t}^{*}-p_{t}
$$

where, $p_{t}^{*}$ is the equilibrium price level and $p_{t}$ is the actual price level.

\section{Equilibrium inflation}

$$
\bar{\pi}_{t}=\tau \pi^{*}+(1-\tau) \bar{\pi}_{t-1}+\varepsilon_{\bar{\pi}, t}
$$

where, $\pi^{*}$ is the steady state inflation, while $\bar{\pi}$ is the medium-term equilibrium inflation.

Equilibrium price level

$$
p_{t}^{*}=p_{t-1}^{*}+\frac{\bar{\pi}_{t}}{4}+\varepsilon_{p^{*}, t}
$$

where, $\varepsilon_{p^{*}, t}$ is a shock to the equilibrium price level.

Actual price level

$$
p_{t}=p_{t-1}+\frac{\pi_{t}}{4}
$$




\section{P* model with money}

Inflation equation

$$
\pi_{t}=\alpha \pi_{4, t-1}+(1-\alpha) E \pi_{4, t+4}+\beta \tilde{m}_{t-1}+\varepsilon_{\pi, t}
$$

where, $\tilde{m}_{t-1}$ is the real money balances gap, defined as the difference between the logs of actual $(m)$ and equilibrium $(\bar{m})$ money balances.

Real money gap

$$
\tilde{m}_{t}=m_{t}-\bar{m}_{t}+\varepsilon_{\tilde{m}, t}
$$

where, $\varepsilon_{\tilde{m}, t}$ is shock to real money gap.

Equilibrium real money balances

$$
\bar{m}_{t}=\bar{m}_{t-1}+\frac{\mu^{*}}{4}+\varepsilon_{\bar{m}, t}
$$

where, $\mu^{*}$ is steady state real money growth and $\varepsilon_{\bar{m}, t}$ is a shock to equilibrium real money balances.

Equilibrium money growth

$$
\mu_{t}=\tau \mu^{*}+(1-\tau) \mu_{t-1}+\varepsilon_{\mu, t}
$$

where, $\mu_{t}$ is real money growth and $\varepsilon_{\mu, t}$ is a shock to medium-term money growth.

Actual real money stock

$$
m_{t}=m_{t-1}+\frac{\mu_{t}}{4}
$$

\section{$P *$ model with money and trend velocity}

Inflation equation

$$
\pi_{t}=\alpha \pi_{4, t-1}+(1-\alpha) E \pi_{4, t+4}+\beta \tilde{m}_{t-1}+\varepsilon_{\pi, t}
$$

Equilibrium output

$$
\bar{y}_{t}=\bar{y}_{t-1}+\frac{g^{*}}{4}+\varepsilon_{\bar{y}, t}
$$

\section{Output growth}

$$
g_{t}=\tau g^{*}+(1-\tau) g_{t-1}+\varepsilon_{g, t}
$$

All variables in equation (A30) are defined as in equation (A5). 
Actual real GDP

$$
y_{t}=y_{t-1}+g_{t}
$$

Actual interest rate

$$
i_{t}=\rho i^{*}+(1-\rho) i_{t-1}+\varepsilon_{i, t}
$$

where, $i_{t}$ is nominal interest rate and $i^{*}$ is equilibrium nominal interest rate.

\section{Trend in equilibrium velocity}

We generalize more conventional representations of the $\mathrm{P}^{*}$ model by modeling a trend in velocity. In particular,

$$
\Delta v_{t}=\frac{\Delta v^{*}}{4}+\psi\left(i_{t}-i_{t-1}\right)+\varepsilon_{\Delta v, t}
$$

where, $\Delta v_{t}$ is the quarterly change in velocity, $\Delta v^{*}$ is the equilibrium change in velocity, and $\varepsilon_{\Delta v}$ is a shock to the change in velocity.

Equilibrium velocity

$$
v_{t}^{*}=v_{t-1}^{*}+\Delta v_{t}
$$

where, $v_{t}^{*}$ is equilibrium velocity.

Equilibrium money supply

$$
\bar{m}_{t}=\sigma-v_{t}^{*}+\bar{y}_{t}+\varepsilon_{\bar{m}, t}
$$

Real money gap

$$
\tilde{m}_{t}=m_{t}-\bar{m}_{t}+\varepsilon_{\tilde{m}, t}
$$

Real money

$$
m_{t}=m_{t-1}+\mu_{t}
$$

Money growth

$$
\mu_{t}=\tau_{1} \mu^{*}+\left(1-\tau_{1}\right) \mu_{t-1}+\varepsilon_{\mu, t}
$$

\section{Phillips curve models}

See main text. 


\section{APPENDIX II: BAYESIAN PRIORS}

Here we provide the priors for the DSGE and $\mathrm{P}^{*}$ models used for the Bayesian estimation.

Table A2.1. Prior Distribution of the Parameters for the DSGE Models 1/

\begin{tabular}{|c|c|c|c|c|c|c|c|}
\hline \multirow{2}{*}{\multicolumn{2}{|c|}{ Parameter }} & Mean Distribution & St. dev. & & Parameter & Mean Distribution & St. dev. \\
\hline & & nmon parameters & & & \multicolumn{3}{|c|}{ Model-specific parameters } \\
\hline \multirow{12}{*}{ 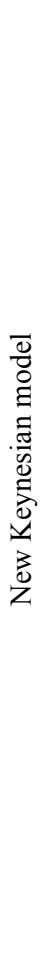 } & $\theta_{\pi}$ & 0.25 beta & 0.05 & \multirow{7}{*}{ 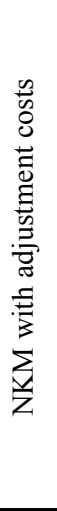 } & $\bar{\gamma}_{y_{t-1}}$ & 0.15 gamma & 0.10 \\
\hline & $\theta_{x_{t}}$ & 0.25 gamma & 0.05 & & $\bar{\gamma}_{y_{t}}$ & 0.75 gamma & 0.10 \\
\hline & $\phi_{x_{t-1}}$ & 0.75 gamma & 0.10 & & $\bar{\gamma}_{E y}$ & 0.20 gamma & 0.05 \\
\hline & $\phi_{E x_{t+1}}$ & 0.15 beta & 0.05 & & $\bar{\gamma}_{i}$ & 1.00 gamma & 0.10 \\
\hline & $\phi_{i}$ & 0.20 gamma & 0.05 & & $\bar{\gamma}_{m_{t-1}}$ & 0.15 gamma & 0.05 \\
\hline & $\rho_{i}$ & 0.80 beta & 0.05 & & $\bar{\gamma}_{E m}$ & 0.15 gamma & 0.05 \\
\hline & $\kappa_{E \pi_{t+1}}$ & 1.50 gamma & 0.20 & & $\tilde{\kappa}_{M_{t}}$ & 0.15 gamma & 0.05 \\
\hline & $\kappa_{E \pi_{t+1}}$ & 0.50 gamma & 0.05 & \multirow{3}{*}{ 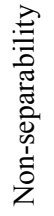 } & $\tilde{\theta}_{m}$ & 0.15 gamma & 0.05 \\
\hline & $\tau$ & 0.10 beta & 0.05 & & $\tilde{\phi}_{m}$ & 0.15 gamma & 0.05 \\
\hline & $g^{*}$ & 2.20 normal & 0.50 & & $\tilde{\phi}_{E m_{t+1}}$ & 0.14 betta & 0.05 \\
\hline & $\rho$ & 0.20 beta & 0.07 & \multirow{2}{*}{ 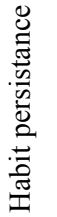 } & $\hat{\theta}_{E m}$ & 0.15 gamma & 0.05 \\
\hline & $r^{*}$ & 2.00 normal & 0.50 & & $\begin{array}{l}\hat{\theta}_{x_{t-1}} \\
\hat{\theta}_{E x}\end{array}$ & 0.05 gamma & 0.05 \\
\hline
\end{tabular}

1/ As the models are nested, the versions with money contain the parameters of the cashless NKM. The modelspecific coefficients are for the lags/leads of the aggregate demand/supply equations and money in the policy rule.

Table A2.2. Prior Distribution of the Parameters for the $\mathrm{P} *$ Models

\begin{tabular}{|c|c|c|c|c|c|c|c|}
\hline \multicolumn{2}{|c|}{ Parameter } & Mean Distribution & St. dev. & & Parameter & Mean Distribution & St. dev. \\
\hline \multicolumn{4}{|c|}{ Common parameters } & \multicolumn{4}{|c|}{ Model-specific parameters } \\
\hline \multirow{4}{*}{ 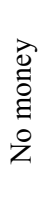 } & $\alpha$ & 0.25 beta & 0.05 & ? & $\psi$ & 2.10 normal & 0.30 \\
\hline & $\beta$ & 0.25 gamma & 0.05 & $\frac{0}{9}$ & $\sigma$ & 108.40 normal & 50.00 \\
\hline & $\tau$ & 0.10 beta & 0.05 & $\overrightarrow{\widetilde{\sigma}}$ & $\tau$ & 0.30 normal & 0.10 \\
\hline & $\pi^{*}$ & 2.00 normal & 0.30 & 仓ั & $\tau_{1}$ & 0.03 normal & 0.10 \\
\hline \multirow{6}{*}{ 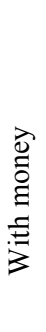 } & & & & $\underset{\Xi}{\Xi}$ & $\pi^{*}$ & 2.00 normal & 0.30 \\
\hline & $\alpha$ & 0.25 beta & 0.05 & E & $g^{*}$ & 2.50 normal & 1.00 \\
\hline & $\beta$ & 0.25 gamma & 0.05 & $\underset{\Xi}{\bar{\Xi}}$ & $\mu^{*}$ & 4.00 normal & 1.50 \\
\hline & $\tau$ & 0.30 normal & 0.10 & ֻँّ & $i^{*}$ & 4.50 normal & 1.00 \\
\hline & $\pi^{*}$ & 2.00 normal & 0.30 & 㯊 & $\Delta v^{*}$ & -0.50 normal & 1.50 \\
\hline & $g^{*}$ & 2.50 normal & 1.00 & $\stackrel{5}{3}$ & $\rho$ & 0.30 normal & 0.10 \\
\hline
\end{tabular}

